\title{
SHARED Business CULTURE VALUE: AN ANTHROPOLOGICAL STUDY OF THE ENDOGENOUS MECHANISM OF ISLAMIC FOOD SAFETY IN CHINA
}

\author{
ROBERT GUANG TIAN \\ SHANTOU UNIVERSITY \\ AND SHIRLEY YE SHENG \\ BARRY UNIVERSITY
}

\begin{abstract}
This study proposes a conceptual model of a "Shared Business Culture Value" as the endogenous mechanism of Islamic food safety in China. We conducted one-to-one anthropological in-depth interviews with 43 managers and staff, together with a field study, by giving unstructured and structured questionnaires to 398 consumers from ten Islamic restaurants in Yinchuan city, China. Our study reveals that the operation of Islamic food industry is strongly related to the Islamic faith, which advocates "cleanliness and healthiness". We found this shared life-value is helpful in developing a shared business-culture value and mutual trust between business and customers. Our model is both theoretically relevant and managerially useful. Insights generated from our research are valuable for managing the food industry in China: (1) to build a "mutual benefits and morality" view; (2) to nurture social empathy; and (3) to promote the growth of a shared business culture value.
\end{abstract}

Keywords: shared business culture value, food safety, management mechanism, mutual benefit and morality, culture value, social empathy 


\section{Introduction}

Unsafe food incidents have frequently occurred, even though the Chinese government has made great efforts to eliminate it. It has raised crises and impacted upon the stability and development of Chinese society. A recent study shows that consumers still have little confidence in food safety in China (Liu and Wang, 2013). The previous models of food safety administration mainly focused on legislation and supervision. They are regarded as a method of governing by external forces. In other words, food producers and service providers passively receive supervision and administration from government and the public. When supervision is lacking, or is not fully functional, then unsafe food incidents occur from time to time. Zhang, Qiao and Huang's study (2013) shows that 26.9 per cent of Chinese consumers do not trust Food Safety Certification even if it is issued by the Chinese government or by a third-party food-safety accreditation organization. It is therefore very important and urgent for the Chinese food industry to propose a more comprehensive model of food safety administration.

The major parties responsible for food safety are those involved in food manufacturing and services. Their values and ideology provide vital guidance for their conduct and work-ethic. How to make the food produces and service providers voluntarily responsible for food safety is an important task, especially in the current economic transition period in China. Consumers are the main cognitive body for food safety. Their trust in food industry and trust-building mechanisms constitute the core of safety cognition. The classical research into trust shows that the frequent occurrence of food safety incidents is due to asymmetric information between buyers and sellers. However, Tao and Zhou (2012) state that information asymmetry is an inevitable and unsolvable problem, especially in the transaction of consumer goods and experiential products.

In a market with asymmetric information, a consumer's purchase decision is based more on his trust in the company or brand than in his knowledge of the product. In other words, there exists a trust mechanism in the market with asymmetric information. Therefore, if an effective trust mechanism can be developed, then the problem caused by information asymmetry will be avoided. Food safety management is a complex system. Can a common value shared by producers and consumers provide us with a new trust mechanism that will solve food safety problems?

This study focuses on the impact of Islam on safety values. We will propose an endogenous mechanism of the Islamic food safety model based on in-depth interviews and surveys. The new model will provide us with 
an internal control method of food safety management. Our contribution to this study is a proposed conceptual model that converts food safety management from an external control to an internal control, and guided by this mechanism, the practitioners in the food industry under our study will voluntarily produce and serve safe food. This mechanism may provide a new stream of thought to solve the food safety problem in China. Meanwhile, our study may help to propel the food industry to build a competitive advantage originating in the consumer's value of food safety, increase consumer trust in the food produced in China, and eventually improve the competitiveness of the Chinese food industry.

\section{Literature Reviews and Model Conceptualization}

Academia has reached a consensus that the food safety issue should be co-governed by society (Qi, 2017; Tao et al., 2017; and Li, 2016). Thus, the trust mechanism among the multiple co-governance subjects is a key issue. Only a limited number of previous studies have researched into trust mechanisms of food safety. Chen, Zhao and Cao (2014) pointed out that a trust mechanism can be built through market centralization, reducing market intermediaries, acknowledging major members in the value chain, and safeguarding the company's business reputation. Tao and Zhou (2012) believe that the following two conditions must be met to build a trust mechanism of food safety. First, it is the condition of generation. High quality is reflected in a premium price, which resonates with Gresham's law that "good money drives out bad". Second, it is the condition of stabilization. A premium price is secured with high quality. In other words, "premium price promotes high quality". Thus, Tao and Zhou proposed that a trust mechanism of food safety could exist between food providers (i.e. producers, sellers, and service providers) and consumers. Because there exists inevitable information asymmetry, food industry practitioners and consumers cannot establish mutual trust, thus a mediator is needed to link both ends and convey trust. Normally, there are three types of mediator: (1) The government's regulatory system and legitimate power over food industry practitioners. Thus, consumers will transfer their trust from governmental authority to food industry practitioners; (2) Accreditation to food industry practitioners issued by government or third-party organizations. Therefore, consumers can shift their trust from accreditors to food providers; and (3) Brand equity development by food industry practitioners. Consumers transfer their trust from the brand to the product and the service. In reality, the first type of trust mechanism is still immature. Because of the frequent occurrence of unsafe food incidents, the 
authoritative image of government rule and regulation in this regard is not completely established in the minds of consumers. The second and the third types of trust mechanisms failed as well. Zhang et al. (2013) study demonstrates that only 39.6 per cent of consumers trust government certification, third-party accreditation, or established brand equity. Can a new and reliable trust mechanism be developed? Through our field study, we found that the Muslim restaurants operated by the Hui (Chinese Muslims) strictly forbid customers from bringing in non-Muslim food (such as pork products) to consume. In addition, the raw food material must come from strictly halal sources, and particularly, raw meat should be butchered according to a strict procedure. Muslim law requires that animals should be killed along with chanting of the Holy Quran by an Imam. Animals not ritually slaughtered are absolutely forbidden from being processed into Islamic food. Devout Muslims will eat only halal food. If there is no nearby Muslim restaurant available on their (e.g.) business trip, Muslim consumers would usually take some convenient Islamic food (such as instant halal noodles) with them. If by chance they find a halal restaurant in a non-Muslim community, they will likely investigate it by chatting with the restaurant employees to ascertain whether the restaurant is truly Muslim before patronizing the business. This provides us with an insight: the common ground that both Muslim food providers and consumers are seeking is the Islamic "halal" standard. We therefore conceptualize a trust mechanism of food safety as following: religious belief can serve as a mediator for mutual trust between buyers and sellers. Furthermore, shared cultural values are a new pattern of food safety mechanism.

\section{Empirical Research Procedure}

\section{Experiment Design}

At present, China is at a social transition stage, a new era with multiple values. In this situation, it is not easy to achieve a credible, commonlyacknowledged "shared business-culture value". Shared business culture values refer to the law and order of value that is approved and voluntarily complied with by people during the business processes of production, circulation, service and consumption. It is related to how a company will strike a balance between profits and its corporate social responsibility during production and transaction; and how a consumer, on the other side, will balance his expenses and his social responsibility during consumption. The Confucian culture, deeply rooted in traditional mainstream culture in 
China, places business and profits at the bottom of the value framework. Thus, business and profits were suppressed for a very long time in Chinese history (Zhu and Yong, 2014). Consequently, business culture in China was weak, reflected in such value-defects as "insufficient rational wealth value", "inadequate wealth rule", and "low socialized-wealth responsibility" (Yong et al., 2014). After economic reforms and opening-up policies in the late 1970's, the Chinese people's profits-pursuing motives were greatly amplified, to an unprecedented extent. The old moral-based value system was destroyed, but a new value system hasn't yet been formed. However, a "moral-and-benefit compounded" society has formed in this time. Although developing shared culture-values is a long-term course, Muslim culture, as a subculture, can provide a template of "shared business-culture value".

"Cleanliness", a distinctive characteristic in Islamic culture, is a requirement of every Muslim believer. According to Islamic law, all clean things are lawful, and any dirty item is unlawful. Quoted from the Quran (Ma, 1981), "He permits your access to beautiful things and forbids you from dirty stuff"; Muhammad said, "You should prefer to be clean, because Islam is a clean religion", and "hygiene is a part of religious belief". He emphasized the importance of cleanliness, and highlighted the purity of Islam. In order to keep both mind and body clean, believers should perform Wudu and Ghusl before formal religious activities. Islamic food production must meet the standards of being "clean" throughout the whole production process. Food processing must be handled in a clean place by Muslims only, who must perform Ghusl and cite "tai-si-mi" (in the name of Allah) prior to work. During the whole food-processing procedure, the worker should ritually comply with Muslim laws and demonstrate his seriousness, earnestness, and responsibility, which would help to prevent fake, adulterated or toxic food from being produced, and therefore assures the safety, hygiene and healthiness of Muslim food.

Unlike traditional Chinese culture, discussed above, Islamic culture encourages its adherents to be engaging, keen on, and good at doing business. Halal is a worldly representation of Islamic culture; therefore, a shared business culture value is an important part of Islamic culture. This study aims to explore the role of halal culture in the development of the trust mechanism of food safety, construct the "shared business culture value" model, and further provide a new framework for food safety management in China.

The whole study will be carried out by studying both Islamic food practitioners and consumers with the following two research methodologies: a field study, and a business-anthropological style of in-depth interviews ( $\mathrm{Li}$ and Tian, 2014). When Muslim food practitioners obey the faith-directed 
guidelines to produce, process, and serve foods, then Islamic foods are consumed by customers with the confidence that Muslim culture can guarantee. Hence, we conclude that Islamic culture contributes to the development of the shared business-culture value. We have interviewed food industry practitioners with set interview outlines, both individually and in groups. We also used questionnaires to survey consumers individually or in groups about their perceived food safety.

\section{Interviewing Muslim Food Practitioners}

\section{Interview Outlines and Contents}

(1) Measuring respondents' knowledge about Islamic culture: The objective here is to survey the respondents' knowledge of Islamic customs, especially the diet taboos, and discover the role of Muslim rules in their business practices.

(2) Examining the roles of Islamic culture on food safety. Sample questions include:

1. Does the company under survey strictly observe Muslim taboos?

2. What role has religious belief played in the production and service of Muslim food?

3. Has your company ever used gutter oil or fake mutton in food processing?

4. Would you choose to use gutter oil if it was marketed to you? If not, why? Is it for religious reasons, or because you adhere to the criminal and civil law? If for both, please tell us which one weighs more.

\section{Interviewees}

We interviewed seven managers and 36 members of staff from ten Muslim restaurants in Yinchuan. Among the 36 staff, eight were chefs and 28 were waiters. All seven managers, and 28 out of the 36 staff, were Hui (Muslim Chinese). The remaining eight staff, including two chefs and six staffs, were Han, non-Muslim.

\section{Interview Reports}

(1) Knowledge about Islamic food

Ninety-five per cent of the interviewees (41 out of 43 participants) held the view that if the owner(s) /manager(s) of the restaurant is (are) Hui, it is 
a Muslim restaurant, serving Islamic food. They pointed out that even if the respondent was a Hui Muslim, but did not strictly practice Islam, then the food served in his restaurant would not be halal. Hui ethnic interviewees were proud of their religion and nationality. The necessity for cleanliness and healthiness was commonly agreed by all respondents, although their restaurants vary in size and quality. However, the eight Han interviewees' knowledge of Muslim customs was limited. Although they all knew that Muslims are not allowed to eat pork, only a few of them could list other prohibited items such as alcohol, dog meat, donkey meat, etc. These non-Muslim interviewees respect and understand that Muslims have worship needs and religious rituals, such as Ramadan, Wudu, and Ghusl. However, they think that Islamic rituals are related to religion only, and therefore have no impact on Muslim employees' work behaviour .

(2) Knowledge of major steps in food operation

All the seven managers/owners believed that raw material procurement is the most important step, then in order of importance ranked cooking, marketing, and storage. Among the list of raw materials, the meat category (beef, mutton, and poultry) was the most critical, then came cooking oil, condiments, eggs, vegetables, rice and flour, etc. The importance of job titles was listed in such an order: management, procurement, chef, steward, expeditor and porter. Recruiting priority is given to those Muslims with connections such as relatives, fellows from hometown villages, and friends. Then other unknown Hui ethnic folks will be considered. The nonMuslims (mainly Han) are the last to be considered. The reported reason for this was because "hiring Muslim employees makes it convenient to communicate and manage, strengthens the reputation of Muslim restaurants, and attracts customers".

(3) Examining the impact of Muslim belief on the Islamic food business

Among the 43 interviewees, 39 (90.7 per cent) stated that Islamic culture has a very positive influence on Islamic food operation. They all claimed that their operations strictly abide by Muslim rules, especially with regard to maintaining hygiene and procuring raw meat and eggs. They also reported that it is because of their observation of Islam and their routine. Our Muslim interviewees' consensus was that if they failed to follow Islamic rules, they would suffer from a bad conscience. Thirtyeight respondents believed that the most critical part in Muslim catering business is the procurement of raw materials. If using fake materials such as gutter oil and fake mutton, harmful and poisonous materials, and eggs 
and vegetables from unidentified sources are used, then the foods made from them will violate both Muslim and state law. In addition, it is detrimental to the firm's reputation; and they would be despised by relatives and friends. Money earned unethically way is "not spendable," and if given to elders and children is regarded as "sin to $\sin$ ". The interviewees all believed that controlling the sources of meat in the strictest way is a vital step. They reported that they use regular suppliers, who have excellent reputations and hold strong religious beliefs (some of them reported purchasing meat from the wholesale beef and mutton market in the well-known Nanguan mosque). They strongly reject the use of gutter oil or fake mutton. They claim that "those materials are too dirty" and "those actions are against conscience and law". Some of our respondents stated that completely forbidding alcohol consumption in their restaurants is not easy, as it may hurt their business. However, three alcohol-free restaurants, namely Tong Xin Chun, Yi Shen Xuan and San Yi Xuan devoutly practice halal catering.

\section{Summary}

Hui employers and employees are well aware of Islamic culture and food. As in-group members, they identify Islamic food enterprises that share their religious beliefs and ethnic identity. This demonstrates that Muslim belief is an antecedent to in-group identity in the Muslim food industry. Not only does the Muslim belief guide the progress of food preparation and service, but it has also disseminated into daily management routines and staff conduct. Furthermore, these firms hire Hui Muslims and control the key processes of production and service to assure the quality of Islamic food. Hence, Islamic culture, acting as a business culture, is deeply rooted in the Islamic food industry.

\section{Investigating Perceived Muslim Food Safety by Consumers}

\section{Questionnaire development}

There are two types of consumers of Islamic food: regular Muslim consumers who consume only Islamic food, and those selective nonMuslim consumers who occasionally consume Islamic food as an alternative. Regular consumers are loyal to Islamic foods because of their religious belief; their perception of Islamic food and their reasons for purchasing it reflect general Islamic cultural values, while the selective consumers' answers to these same questions attest to the effects of Islamic 
culture on food safety.

Guided by this insight, we randomly interviewed 21 respondents, including professors, students, and friends of one of the co-authors of this paper, on a one-to-one basis. Among them, eight were Hui Muslims and the other 13 Han Chinese. We asked, "In your opinion, which is safer, Islamic food or non-Islamic food? Please justify your choice." Five Hui respondents claimed that "Islamic food is safer because it is not only subject to state laws but also religious rules. If you disobey Muslim law, Allah will punish you." Two of our Hui respondents answered, "Not sure." Their reason was that Muslim food ought to be safer but fake Islamic food is sold in the marketplace and thus makes the answer to this question uncertain. One Hui interviewee replied, "cannot answer," as he had never previously considered the matter. Seven out of the 13 Han interviewees stated that Islamic food should be safer than non-Islamic food because the Hui minoriy strictly abides by the Muslim religion. In addition, they acknowledged that many items are forbidden from being used in food processing or being eaten, and Muslim restaurants usually seemed cleaner than others. Four Han respondents answered that it was hard to say, because today's businessmen are chasing profits and paying no regard to health and safety. The other two Han interviewees responded "not sure," as they have never tried Muslim food and thus could not offer comparisons.

Based on our interview, we designed a partially-unstructured, and partially-structured questionnaire. We invited six experts, two of whom were Hui ethnologists and the others were specialists in each of these areas: Islamic food, management, marketing, and organizational behaviours. They were invited to discuss the dimensions and items of the questionnaire, and their opinions used to develop the final formal questionnaire to investigate consumers, perceptions of Islamic food safety. Our questionnaire had three parts. Part one was demographic information, including place of ancestry (the purpose of this item is to know if the respondent was brought up in a Muslim community), gender, age, ethnicity, and religion. Part two examined the consumer's perceptions of Islamic food safety. The following sections were included, with all items structured on a 1 to 5 scale: (1) the level of knowledge about Islamic food ( 1 as unfamiliar and 5 very familiar); (2) the level of knowledge about Islamic culture ( 1 as unfamiliar and 5 very familiar); (3) the level of attention to food safety issues ( 1 as the least and 5 as the most); (4) the perceived level of food safety ( 1 as the least and 5 as the most); (5) the perceived level of strictness in practicing Muslim rules during food processing and selling ( 1 as the least strict and 5 as the most strict); and (6) evaluating the general status of Muslim food safety (from 1 to 5 
respectively listed as very safe; safe, but there are some problems; unsure; there are solvable problems; and disappointing).

Part Three examined the relationship between the consumer's perception of Islamic culture and Islamic food safety. This part was also structured with a 1 to 5 scale. Major questions are: (1) Is Islamic food safe if it is processed and delivered according to Islam's dietary taboos (1 as least safe to 5 as most safe); (2) The impact of the Islamic religion on food safety ( 1 as no impact to 5 as great impact).

In order to improve the quality of responses, we included an introduction to our survey. We stated clearly that respondent's anonymity would be preserved; that the data collected was only for research purposes; and that the response to each question was not going to be judged and only group data would be analyzed. Next, we trained our investigators in how to conduct the survey: they conducted it collectively, and participants could consult investigators on the scene when needed.

\section{Participants}

450 questionnaires were distributed. After excluding missing and incomplete questionnaires, 398 valid questionnaires were collected. The demographic information shows the following profile.

(1) Place of ancestry: 214 participants reported Ningxia as their place of ancestry (Hui community), and 114 were from other places of ancestry (other nationality regions);

(2) Gender: 176 were male and 222 female;

(3) Age: 325 participants were below 35 years old, 58 between $35-55$, and 12 over 55;

(4) Ethnicity: 111 were Hui, 259 were Han, and 28 were other nationalities;

(5) Religion: 114 were Muslims, 284 non-Muslims.

\section{Data Description}

(1) Cognition of Islamic food and Islamic culture

The results illustrate how well participants know about Islamic food and Islamic culture. The perceptions were measured according to these two parameters: (1) general knowledge about Islamic food; and (2) knowledge about specific elements in Islamic culture, such as ideology, rules, rituals, and stories. The results are summarized Table 1. 
(2) Perception of Islamic food safety by consumers who are familiar with Islamic food and culture.

We selected the results from participants who responded that they knew Islamic culture and food "very well" or "relatively well", and the results from those classifying themselves as "Muslim" and "non-Muslim" for a further comparison (see Table 2).

Table 1. Consumers' Cognition of Islamic Food and Culture $(n=398)$

\begin{tabular}{llrrrrr}
\hline & & $\begin{array}{r}\text { very well } \\
(\%)\end{array}$ & $\begin{array}{r}\text { relatively } \\
\text { well } \\
(\%)\end{array}$ & $\begin{array}{r}\text { not sure } \\
(\%)\end{array}$ & $\begin{array}{r}\text { a little } \\
(\%)\end{array}$ & $\begin{array}{r}\text { unfamiliar } \\
(\%)\end{array}$ \\
\hline Islamic & Total & 70 & 130 & 141 & 55 & 2 \\
Food & & $(17.59)$ & $(32.66)$ & $(35.42)$ & $(13.82)$ & $(0.50)$ \\
& Hui & 49 & $50(44.64)$ & 12 & $1(0.90)$ & \\
& & $(43.75)$ & & $(10.71)$ & & 122 \\
& Han & 15 & $75(29.41)$ & 42 & 1 \\
& & $(5.90)$ & & $(47.84)$ & $(16.47)$ & $(0.39)$ \\
Islamic & Others & 6 & 5 & $7(22.58)$ & 12 & 1 \\
Culture & Total & $(19.35)$ & $(16.12)$ & & $(38.70)$ & $(3.22)$ \\
& & 48 & 110 & 134 & 102 & 4 \\
& Hui & $(12.06)$ & $(27.63)$ & $(33.67)$ & $(25.63)$ & $(1.00)$ \\
& Han & $(29.73)$ & $59(53.15)$ & 12 & $6(5.40)$ & \\
& & 13 & $47(18.00)$ & 113 & 84 & 4 \\
& Others & $(4.98)$ & & $(43.30)$ & $(32.18)$ & $(1.53)$ \\
& & $(7.40)$ & $(14.81)$ & & $(44.44)$ & \\
\hline
\end{tabular}

(2) Perception of Islamic food safety by consumers who are familiar with Islamic food and culture.

We selected results from participants who responded know Islamic culture and food "very well" and "relatively well" and the results from those classified themselves as "Muslim" and "non-Muslim" for a further comparison (see Table 2). 
Table 2. Perception of Islamic Food Safety by Consumers Who Are Familiar to Islamic Food and Culture

\begin{tabular}{lcrrrrr}
\hline & & $\begin{array}{r}\text { very safe } \\
(\%)\end{array}$ & $\begin{array}{r}\text { relatively } \\
\text { safe }(\%)\end{array}$ & $\begin{array}{r}\text { not sure } \\
(\%)\end{array}$ & $\begin{array}{r}\text { relatively } \\
\text { unsafe } \\
(\%)\end{array}$ & $\begin{array}{r}\text { not safe } \\
\text { at all } \\
(\%)\end{array}$ \\
\hline Total & $(\mathrm{n}=398)$ & 59 & 181 & 141 & 12 & 5 \\
& & $(14.82)$ & $(45.48)$ & $(35.43)$ & $(3.02)$ & $(1.26)$ \\
Familiar & $\left(\mathrm{n}_{1}=200\right)$ & 44 & 97 & 48 & 9 & 2 \\
with & & $(22.00)$ & $(49.50)$ & $(24.00)$ & $(4.50)$ & $(1.00)$ \\
$\begin{array}{l}\text { Islamic } \\
\text { Food }\end{array}$ & & & & & & \\
Familiar & $\left(\mathrm{n}_{2}=158\right)$ & 42 & 74 & 37 & 5 & \\
with & & $(26.58)$ & $(46.84)$ & $(23.42)$ & $(3.16)$ & \\
$\begin{array}{l}\text { Islamic } \\
\text { Culture }\end{array}$ & & & & & & \\
Muslim & $\left(\mathrm{n}_{3}=114\right)$ & 44 & 59 & 11 & & \\
& & $(38.60)$ & $(51.75)$ & $(9.65)$ & & \\
Non- & $\left(\mathrm{n}_{4}=284\right)$ & 15 & 122 & 130 & 12 & 5 \\
Muslims & & $(5.28)$ & $(42.96)$ & $(45.77)$ & $(4.23)$ & $(1.76)$ \\
\hline
\end{tabular}

(3) Perception of food safety, given that Islamic food is processed and abiding delivered strictly by Islamic rules.

It serves as proof that Islam assures food safety when the consumer's high perception of safety is because Islamic food is processed and delivered strictly according to Islam. The participants are the same as those in Table 2. Our results are show in Table 3.

(4) Perception of the roles of Islamic culture in promoting food safety The culture's self-constraining roles on food safety is the embodiment of its precious soft power. The participants in this session of study are the same as those in Table 2. The results in Table 4 reflect the consumer's perception of food safety in the Islamic culture. 
Table 3. Perception of Food Safety Due to the Facts that Islamic Food is Processed and Delivered Strictly Abide by Islamic Rules

\begin{tabular}{lcrrrrr}
\hline & & $\begin{array}{r}\text { very safe } \\
(\%)\end{array}$ & $\begin{array}{r}\text { relatively } \\
\text { safe }(\%)\end{array}$ & $\begin{array}{r}\text { not sure } \\
(\%)\end{array}$ & $\begin{array}{r}\text { relatively } \\
\text { unsafe } \\
(\%)\end{array}$ & $\begin{array}{r}\text { not safe } \\
\text { at all } \\
(\%)\end{array}$ \\
\hline Total & $(\mathrm{n}=398)$ & 47 & 234 & 93 & 18 & 6 \\
& & $(11.81)$ & $(58.79)$ & $(23.37)$ & $(4.52)$ & $(1.51)$ \\
Familiar & $\left(\mathrm{n}_{1}=200\right)$ & 38 & 122 & 30 & 9 & 1 \\
with & & $(19.00)$ & $(61.00)$ & $(15.00)$ & $(4.50)$ & $(0.50)$ \\
$\begin{array}{l}\text { Islamic } \\
\text { Food }\end{array}$ & & & & & & \\
$\begin{array}{l}\text { Familiar } \\
\text { with }\end{array}$ & $\left(\mathrm{n}_{2}=158\right)$ & 37 & 82 & 32 & 6 & 1 \\
Islamic & & $(23.42)$ & $(51.90)$ & $(20.25)$ & $(3.80)$ & $(0.63)$ \\
Culture & & & & & & \\
Muslim & $\left(\mathrm{n}_{3}=114\right)$ & 35 & 72 & 7 & & \\
& & $(30.70)$ & $(63.16)$ & $(6.14)$ & & \\
Non- & $\left(\mathrm{n}_{4}=284\right)$ & 12 & 162 & 86 & 18 & 6 \\
Muslims & & $(4.23)$ & $(57.04)$ & $(30.28)$ & $(6.34)$ & $(2.11)$ \\
\hline
\end{tabular}

(4) Perception of the role of Islamic culture in promoting food safety The culture's self-constraining role in food safety is the embodiment of its precious soft power. The participants in this section of the study are the same as those in Table 2. The results in Table 4 reflect the consumer's perception on food safety in Islamic culture.

Table 4. Perception and Assessment of the Vital Role of Islamic Culture in Promoting Food Safety

\begin{tabular}{lcrrrrr}
\hline & & $\begin{array}{r}\text { very } \\
\text { important } \\
(\%)\end{array}$ & $\begin{array}{r}\text { somewhat } \\
\text { important } \\
(\%)\end{array}$ & $\begin{array}{r}\text { not sure } \\
(\%)\end{array}$ & $\begin{array}{r}\text { not } \\
\text { important } \\
(\%)\end{array}$ & $\begin{array}{r}\text { not at } \\
\text { all (\%) }\end{array}$ \\
\hline Total & $(\mathrm{n}=398)$ & 72 & 243 & 50 & 26 & 7 \\
& & $(18.09)$ & $(61.06)$ & $(12.56)$ & $(6.53)$ & $(1.76)$ \\
$\begin{array}{l}\text { Familiar } \\
\text { with }\end{array}$ & $\left(\mathrm{n}_{2}=158\right)$ & 39 & 99 & $11(6.96)$ & 6 & 3 \\
$\begin{array}{l}\text { Islamic } \\
\text { culture }\end{array}$ & & $(24.68)$ & $(62.66)$ & & $(3.80)$ & $(1.90)$ \\
Non- & & & & & & \\
Muslim & $\left(\mathrm{n}_{3}=114\right)$ & 25 & 69 & 15 & 4 & 1 \\
Non- & $\left(\mathrm{n}_{4}=284\right)$ & $(21.92)$ & $(60.53)$ & $(13.16)$ & $(3.50)$ & $(0.88)$ \\
Muslims & & $(16.55)$ & 174 & 35 & 22 & 6 \\
\hline
\end{tabular}




\section{Summary}

(1) The high perception level of food safety in Muslim food.

More than 60 per cent of respondents from our sample thought that Islamic food was safe, among them, "very safe", "relatively safe" and "not safe" were respectively 14.28 per cent, 45.48 per cent, and 4.28 per cent.

(2) Knowledge of Islamic food and culture play an important role in the perception of food safety.

50.25 per cent of our sample claimed they were very familiar or relatively familiar with Islamic food, and we put them in the "high familiarity with Islamic food" group. 39.69 per cent of our sample stated that they were very familiar or relatively familiar with Islamic culture, thus we put them in the "high familiarity with Islamic culture" group. A total of 71.5 per cent of high familiarity with Islamic food participants claimed Islamic food is safe, including 22 per cent who answered "very safe", and 49.5 per cent who chose "relatively safe". Similarly, a total of 73.42 per cent of high familiarity with Islamic culture participants claimed Islamic food is safe, including 26.58 per cent who responded "very safe", and 46.84 per cent who indicated "relatively safe". Comparing Islamic consumers who have "high familiarity with Islamic food and culture" with their non-Islamic counterparts, 48.24 per cent answered that Islamic food is "very safe", and 42.07 per cent responded "relatively safe".

(3) The high perception of Islamic food safety is correlated with the consumer's trust in the role that Islamic religion plays in the Islamic food processing, producing, and selling.

Based on the perception that Islamic food is processed and delivered abiding strictly by Islamic rules, 11.81 per cent of respondents stated that Islamic food is "very safe", and 58.79 per cent answered "relatively safe". The figure rises to 19.5 per cent (very safe) and 61 per cent (relatively safe) respectively, among high familiarity with Islamic food participants. The figure is even higher when it is measured among Muslim counterparts, showing 30.7 per cent (very safe) and 63.16 per cent (relatively safe). With a further look at the perceived role of Islamic culture on food safety, 18.09 per cent of participants answered "very important", and 61.06 per cent responded "somewhat important". These figures show a slight increase among participants of high familiarity with Islamic culture, showing 24.68 per cent (very important), and 62.66 per cent (somewhat important) respectively. 


\section{Discussion}

\section{The Mechanism of "Shared Commercial Culture Value" in Food Safety Management}

It is surprising that Islamic food receives higher food safety recognition while nationally the overall food industry is suffering from low trust. Ye's (2014) survey on "the cognition of food safety and consumer behaviour" of a sample of 366 respondents in Wuhan city illustrates that 99.2 per cent show concerns with food safety, and among them 54.1 per cent show great concern, or are even scared about food safety. Sun et al. (2013) investigated 102 consumers' grading on food safety. No respondents chose the 90-100 band; 11 chose the 70-90 band, which accounts for 10.78 per cent; 57 chose the 50-70 band, which takes 55.88 per cent; and 34 graded below 50, which is 33.33 per cent. It is apparent that Islamic food has a special management mechanism for food safety. This mechanism can have great value in our society if it can be applied beyond the ethnicity boundary, and is widely used in supervising food producing, serving and consuming.

We conceptualized an original model of "Mechanism of Shared Business-Culture Value" based on the analysis of the results from the above-mentioned interviews and survey.

Religious beliefs provide the value source for Islamic food industry. Both business and consumers are faithful to the Islamic religion, which they follow exclusively and piously. Islamic believers are respectful toward mighty Allah and his Messenger. Therefore, believers undoubtedly comply in their conduct with the will and words of Allah and his Messenger. They often guiltily reflect on their behaviour, and are afraid of a bad conscience owing to improper conduct. Dietary requirements in Islam are humane. They encourage Muslims to enjoy delicious food, but also forbid certain foods to be consumed. Forbidden food cannot be consumed, and it cannot be traded for profit, either. Islam advocates that Muslims engage in commercial activities for wealth, but it also strictly prohibits unethical gain. "Moral-benefit compatibility" is the basic tenet of Islamic business specifications. "Cleanliness and health" is the business principle of Islamic food. These specifications and principles are deeply rooted in each Muslim's mind via a series of social activities (such as religious education at home and in mosques, and religious rituals) and further guide Muslim' behaviour in life and work, among which diet is most prominent and directly influenced.

Religious beliefs have divine spiritual values, while the culture offers practical spiritual values. Practical spiritual values develop a series of life- 
and work-related rules, rituals, customs, and conventions under the influence of divine spiritual values. Islamic culture manifests the secularization of Islam. The core spirit of Islamic culture is purity, being simple and dustfree. To reach this divine core spirit, the necessary ritual assignments are fasting, bathing, reciting scriptures, and worship. The Islamic ways, involving in the aspects of body, mind, conduct and diet, have been deeply internalized by Islamic individuals, and thus they learn self-restraint and social activities, including commercial activities. In the case of food production, catering, and consumption, a pious Muslim has already internalized the principle of "cleanliness and health" into his behaviour.

Social orders are formed in two ways. One order is formed from top to bottom, through administrative power. The other order is formed spontaneously through beliefs and values. The administratively formed order is systematic, mandatory, and standardized. The voluntarily formed order is spontaneous, situational and culturally-retrained (Yong and Zhu, 2013). From a human behavioural-structure point of view, an administratively formed order is an external control type in which individuals passively obey rules to avoid punishment. Thus, this type of order will lead to an "external-balance" status. By contrast, the voluntarily formed order is an internal control type in which individuals spontaneously resonate with their feelings and reach an "internal-balance" status. The administratively formed order is systematic and standardized, but it requires large investments and cannot be easily supervised. In fact, a great deal of investment has already been put in to administrating food safety. However, the results are still not satisfying. On the contrary, the voluntarily formed order has self-restraint power and can maximize management efficiency. The Islamic food safety management that is greatly influenced by the Islamic business culture provides us with an excellent example of a voluntarily formed order. The "Islamic way" has been rooted in everyday life in Islam. It is collectively and unconsciously echoed by groups of Islamic consumers. No matter whether it's the food producers or consumers, whoever disobeys Islamic discipline will cause an internal psychological imbalance owing to deep feelings of guilt about their misconduct. This inherent order among Muslims assures mutual trust between producers and consumers. In other words, consumers will trust the food because they trust the people who provide it.

Viewing the mechanism of Islamic food safety, we conclude that if religion is the source of belief, then belief is the foundation of value, and value is the key to behaviour, and proper behaviour in this case is a guarantee of food safety. Rooted in Islamic belief and religion, the shared value of "cleanliness and health" provides guidance for Islamic food 
operation and consumption. Thus, a "shared culture-value" mechanism of food safety is developed. The term "shared value" refers to the internalized value identified completely by both business and consumers. Such shared values guide the behaviour of both parties to be on the right track according to their belief. Thus, the business operator won't cheat on consumers even under the circumstances of information asymmetry. On the other hand, consumers would trust business operators and be loyal to the business operators who were consistent in practicing their beliefs. "Mutual trust" is thus achieved, based on such shared culture values. Repeated transactions under the "mutual trust" agreement will generate satisfaction between both parties and will even generate pride in their own culture. An internally activated mechanism is thus formed.

\section{The Implication of "Shared Commercial Culture Value" Mechanism to Food Industrial Management in China}

In today's China, the majority of Chinese don't have any religion. Confucianism as a mainstream traditional culture and an ideological system has long been regarded as a quasi-religion, and has exerted huge influence on the Chinese for two-and-a-half thousand years, but Confucianism was developed under an agricultural economic background not comparable with today's socio-economic philosophy. In Chinese history, the food-safety issue was long neglected owing to food shortages over that time. The value and role of food safety was never developed or even mentioned in ancient China. Confucianism is not therefore applicable to the current economic situation and it cannot provide much guidance to food safety.

Today, with abundant living materials available and a rising awareness of humanism, human rights - including the rights to life and health - have become deeply rooted in consumers' minds. Meanwhile, food transactions, in terms of kind, quantity and frequency, have exponentially increased. Consequently, food safety is becoming more and more prominent. Thus, a commonly-acknowledged food-safety value should be constructed to guide food production and consumption and eventually improve the food safety environment.

Although China has historically not had a widely adopted religion, a new social belief system, Core Socialist Values (CSV), has been developed and promoted in today's China. More than just a political belief, the core socialist values are a set of secular beliefs that provide guidance to individual life and conduct. More specifically, there are twelve core socialist values in the set, including the national values of prosperity, 
democracy, civility, and harmony; the social values of freedom, equality, justice, and the rule of law; and the individual values of patriotism, dedication, integrity and friendship. ${ }^{1}$ Maintaining basic life and health is fundamental, and a common core in our society. From our survey results, non-Muslim respondents, like the Muslim ones, also acknowledge that Muslim food is safe. A combined 73.42 per cent of the respondents chose "very safe" and "relatively safe". Only 5.99 per cent responded "unsafe". This demonstrates that Islamic food safety has generated trust beyond religion or ethnic group. Therefore, the righteousness of food safety as consistent with the guidance of core socialist values should be further promoted. Under the guidance of core socialist values, food-safety legislators and policy makers, administrators, producers, service providers, consumers and other related interest groups will reform their individual behaviour according to social responsibility and will be voluntarily involved in maintaining social justice.

To construct the "shared business culture value" of food safety as a social culture, we first need to establish an understanding of the value structure of "moral-benefit compound" (Yong et al., 2014). Confucianism is not applicable in the current economic climate, as it advocates a social value structure of "righteousness over benefit", in other words it advocates righteousness and morality but despises benefits; and it emphasizes the importance of agriculture but abhors business. This moral system guided China for over two-and-a-half thousand years, and thus severely hampered the development of productivity and business innovation in past centuries in China. In Western culture, the value-structure of "righteousness for benefits" has greatly promoted material progress, but it has also generated many social problems. China, as a rising star in the modern business arena should take management expertise from the West and also absorb the best parts of our own traditional culture. Thus, we can construct a cultural value that promotes obtaining benefits righteously and enables benefitmoral mutual growth. Secondly, we shall nurture a social common empathy based on developing a common belief shared by the general public. Lastly, effective actions should be taken to further grow the "shared business culture value".

\section{Conclusion}

Trust is the psychological foundation in the food industry. In the construction of food safety and trust mechanisms, two popular models are

${ }^{1}$ https://en.wikipedia.org/wiki/Core_Socialist_Values 
the reputational mechanism and the supervision mechanism. Essentially, both structures are built in single directions. In other words, both are built through administrative powers from top to bottom with a coercive power to curtail improper conduct. It is a necessary, but not sufficient, condition of the food market. When the rule is compromised (which is a common phenomenon in China), this kind of externally-controlled mechanism will malfunction or reduce its functions. Our research provides a dual-direction trust model based on an internally-controlled mechanism of "shared business culture-value". "Mutual trust" is generated from major players in the food market. The contributions of this study are summarized as follows: (1) expanding and deepening the trust mechanism of food safety in field under study; (2) applying commercial culture to interpret the endogenous mechanism of food unsafety; and (3) providing a theoretical basis for food-safety justice by adopting the Core Socialist Values.

\section{References}

Chen, Y., S.K. Zhao, and F.X. Cao. (2014). "On the Role and Formation of Trust Mechanism in Food Safety”. Journal of Shao Tong School, 36 (1), pp. 59-64.

Li, D.K and T. Guang. (2014). Foodways Anthropology. Yinchuan: Ningxia People Publication.

Li H.F. (2016). On the Social Co-regulation Principle of Food Safety Management in China [J]. Food Industry Science and Technology, 4, pp. 26-29.

Liu, R. and W. Wang. (2013). "Public Bads and Social Development: Dilemma". Economic Theory and Economic management, 6, pp. 6876.

Ma, J. (1981). Quran (translation). Beijing: Chinese Social Science Publication

Qi, J.G. (2017). "New Exploration of Civil Rights in Social Co-regulation of Food Safety". Contemporary Law, 6, pp. 45-53.

Sun, J., G. Yin, H. P. Zhang, K. Yao, W.X. Liu, M.M. Ding, and C. Wang. (2013), "Investigation Research on Food Safety in Pingdingshan City", Agricultural Engineering, 3(4), pp. 77-80.

Tao, G.C., H. Tian, Y.F. Song, and D. Lin. (2017). "Research and Application on the Big Data-based Co-regulation Model in Food Safety Governance", Food Science, access at http://kns.cnki/detail/11.2206.ts.20170628.1635.130.html.

Tao, X.S. and Y.H. Zhou. (2012). "The Study of Trust Mechanism of Food Safety", Issue of Agricultural Economy, 10, pp. 93-99. 
Ye, H. Y. (2014). "Analysis on the Food Safety Consuming Characteristics and Behaviors of Chinese Urban Consumers: An Example of Investigation on the Willingness to Pay for the Traceable Pork in Wuhan", Ecological Economy, 30 (6), pp. 146-150.

Yong, S.H. and L.Y. Zhu. (2013). "Constructive Organizational Behaviors and Destructive Organizational Behaviors: The Chinese Characteristics of Out-role Behavior Model and Its Empirical Study", Chinese Journal of Management, 10 (1), pp. 12-21.

Yong, S.H., J. Wang, and X.Q. Kang. (2014). "In the View of 'More Morality and Less Benefit', Chinese Traditional Industrial and Commercial Culture's Value Defect and Construction", Enterprise Economy, 405 (5), pp. 40-46.

Zhang, Z., J. Qiao, and S.N. Huang. (2013). "Understanding Heterogeneous Preference in Food Safety", Journal of Agrotechnical Economics, 5, pp. $15-104$.

Zhu, L.Y. and S.H. Yong. (2014). "A Comparative study on Value Structure of Confucianism 'Morality and Interest' and the Value Structure of the West - Interests and morality"', Ningxia Social Science, 182(1), pp. 44-50. 